\title{
correspondence
}

\section{Meaning not sentiment}

SiR,--In 'More Comecon cosmonauts' (30 March, page 394) Vera Rich refers to the Russian-Czech joint experiment 'Ekstinktsiya' as an experiment with a "somewhat gloomy name".

I presume that her uneasiness about this name stems from its meaning "extinction", and from the expression 'to become extinct'. Certainly, this literal meaning does not strike a very cheerful note for the astronauts involved in the experiment. However, in astronomy the word 'extinction' is also used to describe the effect which the earth's atmosphere has on the apparent brightness of a celestial body as it comes nearer the horizon and an increasing portion of its light is absorbed by the earth's atmosphere. In the Ekstinktsiya experiment, this effect is used to study the dimming of setting stars through the extinction of their light in a layer of micrometeoritic dust, thereby revealing the density and particle-size distribution of the latter.

Would it not be advisable that a science writer checks on the wider, technical meaning of a word before attaching to it a label expressing a sentimental value?

MART DE GROOT Armagh Observatory, Northern Ireland

\section{Moralistic fallacies}

SIR,-Bernard B. Davis may be right in concluding that scientific enquiry should not be blocked on moral grounds ( 30 March, page 390) but one or two of his more breath-taking generalisations should not pass unchallenged.

- "In fact, one of the historical grounds for racism was the pre-scientific conception of races as permanent, distinct products of creation. But evolution made us aware of the brotherhood of all races". The most influential pre-scientific account of creation for Western civilisation is in the book of Genesis where all men are descended from Adam and Eve and the whole earth is of one language until men in their pride build a tower of Babel. We did not need Darwin's help to discover the brotherhood of man. - ". . . the supernatural basis for a moral consensus was shattered by (Darwin's) elimination of special creation". The Creator's interest in humanity need not be lessened by the possibility that man and the chimpanzee have common ancestors. 'Created in the image of God' is to my mind a better description of man than 'naked ape'. There is certainly something special about the creation of man. Not many of the higher apes read Nature or worry about science and ethics. - ". . the rules of behaviour in any, society... are continually evolving", Does evolution here mean progress ahd if so, what parameters are used to measure it? A few could be suggested: proportion of the society's wealth spent on armaments, divorce rate, contribution to international terrorism. interest in the starving majority of the world. The word evolving may be fashionable in a behavioural context, but it is empty of meaning.

Dr Davis would probably not agree with me that there is a supernatural basis for morality but he should be very clear about the alternatives. The ground of moral conviction to which he refers is very slippery if it depends on a consensus of human wisdom. Attempts to base ethical systems on the natural sciences are doomed to failure. Evolutionary theory has been used, the good being what survives, but this is merely the worship of success. Monod in Chance and Necessity, (Collins, London, 1972) began with the chance origin of life and ended in darkness without any rules. His man-made "ethic of knowledge" requires as much faith as the religious and Marxist systems he dismissed so arrogantly.

Modern science has its roots in the Judeo-Christian view of nature as Hooykaas (Religion and the Rise of Modern Science, Scottish Academic Press, Edinburgh, 1972) has shown. When considering science and ethics we do well to remember that Adam was placed in a garden "to till it and to keep it" (Genesis 2:15). Perhaps there is a message here for the Friends of the Earth too.

\section{University of Nottingham, UK}

J. N. HAWTHORNE

SIR,-If Bernard B. Davis is to convince us that the choice of research should be completelv independent of moral considerations he will have to choose his examples more carefully.

The worst that can be said of Bishop Wilberforce is that he was guilty of intellectual dishonesty in trying to ridicule a case that he did not understand. He met his match in Huxley, and Darwin's theories and conclusions were and continued to be fully discussed. He never suggested proscription. The worst that can be said of Urban VIII is that he was provoked by being identified with the naive Simplicio, constantly defeated in argument, into confining Galileo to his home "having had him shown the instruments of torture". It is true that Galileo's works were suppressed in Italy and where the Pope's writ ran but there was no real attempt to prevent $T$ wo New Sciences being published in Holland. (Really for a Pope he was quite gentle and the offence was mild compared with what he allowed Bernini to do to Rome.) The least evil that might be said of Lysenko is that men died because of his superstitions and his power to enforce them.

Scientists cannot reasonably claim the sole right to judge what risks their * fellow citizens may run as a result of their research activities. Would $\mathrm{Dr}$ Davis accept that soldiers alone should decide which wars we should have? The division is the difference between 'risk assessment' and the acceptability of risk and it ought to be.

London, UK

D. L. Simms

\section{An indifference to facts}

SiR,-Careful students of the nuclear energy controversy have long been aware that the popular journalistic media make little pretense of impartiality in their reporting. usually tilting strongly against the development of nuclear energy. Typically their stories display a careless indifference to facts, employing a mumbo-jumbo terminology that is often irrelevant but is nevertheless sure to contain a quota of "scare" words. Nature, as befits its distinguished scientific reputation, has hitherto been a refreshing contrast; its news stories have related the facts in detail and with scientific precision.

It is therefore all the more regrettable that the description of the radiation leakage at one of the Belgian plants (2 February. page 398 ) is filled with errors, of a pejorative tendency, from start to finish. Presumably the incident involved a release of radioactive iodine-131; instead the contamination is described twice as being 'radium-131'. No such isotope exists, but to the lay mind 'radium' is the more horrific term.

Six people were described as "contaminated by 100 millirems" of the substance. Activity of a contaminating quantity of radioactive material is measured in curies. One guesses that what was meant instead was that the people received exposures (external or internal?) amounting to 100 millirems. The report goes on to say that "The maximum tolerated dose was 3000 millirem for 13 weeks before the possibility of thyroid cancer occurred". It is difficult to reconstruct what this could possibly mean. One recognises in the figures an old (and outdated) 1954 regulation which says that for workers in the field a normal weekly maximum exposure of 300 millirems could be exceeded occasionally if no more than ten times this dose were received in a 13-week period ("Permissible Dose from External Sources of lonising Radiation, Recommendations of the NCRP", NBS

Handbook 59,1954, page 78 ).

What this has to do with iodine-131 is rather obscure. The concern with iodine-131 is that when ingested in various forms it may concentrate in the thyroid. Recommended radiation protection guides relate to internal exposures at the thyroid or to the permissible levels of activity ingested. The kinds of units used and the levels involved are different from those in the report. In any case there is no question of their setting a threshold beyond which thyroid cancer occurs.

It is to be hoped that the reporting in this story was an aberration, and that Nature will in the future resume telling the facts with precision and impartiality. Herbert Goldstein

Columbia University in the City of New York, USA 